
11

.

3

4

5

6

17

8

20

2

5

6

27

8

9

0

\title{
A simplified strategy for sensitive detection of Rose rosette virus compatible
} with three RT-PCR chemistries

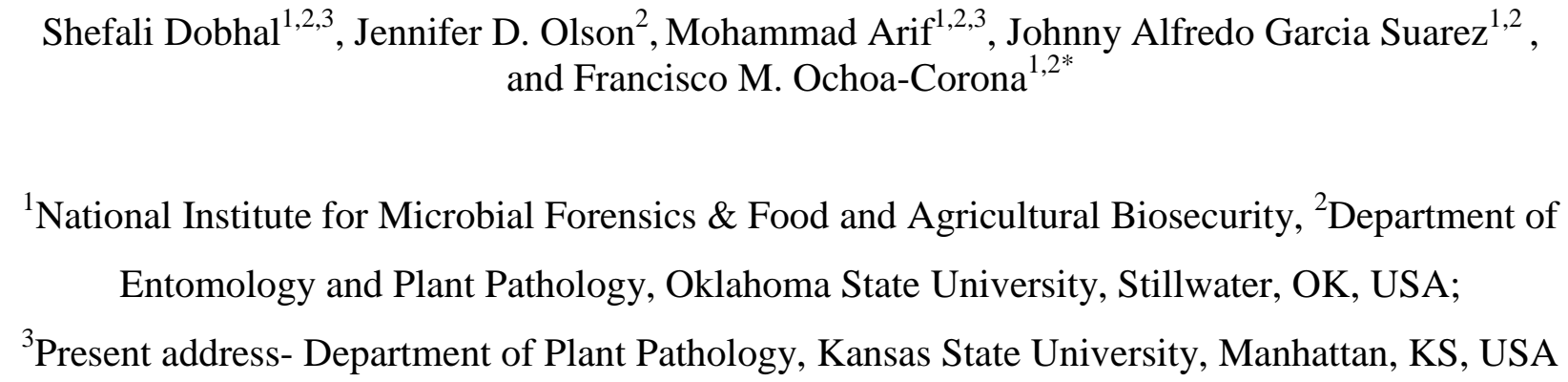
and Francisco M. Ochoa-Corona ${ }^{1,2^{*}}$

${ }^{1}$ National Institute for Microbial Forensics \& Food and Agricultural Biosecurity, ${ }^{2}$ Department of Entomology and Plant Pathology, Oklahoma State University, Stillwater, OK, USA;

${ }^{3}$ Present address- Department of Plant Pathology, Kansas State University, Manhattan, KS, USA

1

23




\section{Abstract}

32 Rose rosette disease is a disorder associated with infection by Rose rosette virus (RRV), a 33 pathogen of roses that causes devastating effects on most garden cultivated varieties, and the 34 wild invasive rose especially Rosa multiflora. Reliable and sensitive detection of this disease in 35 early phases is needed to implement proper control measures. This study assesses a single 36 primer-set based detection method for RRV and demonstrates its application in three different 37 chemistries: Endpoint RT-PCR, TaqMan-quantitative RT-PCR (RT-qPCR) and SYBR Green 38 RT-qPCR with High Resolution Melting analyses. A primer set (RRV2F/2R) was designed from 39 consensus sequences of the nucleocapsid protein gene p3 located in the RNA 3 region of RRV. 40 The specificity of primer set RRV2F/2R was validated in silico against published GenBank 41 sequences and in-vitro against infected plant samples and an exclusivity panel of near-neighbor 42 and other viruses that commonly infect Rosa spp. The developed assay is sensitive with a 43 detection limit of $1 \mathrm{fg}$ from infected plant tissue. Thirty rose samples from 8 different states of 44 the United States were tested using the developed methods. The developed methods are sensitive 45 and reliable, and can be used by diagnostic laboratories for routine testing and disease 46 management decisions.

48 Keywords: Diagnostics; TaqMan RT-qPCR; SYBR-Green RT-qPCR; High Resolution Melting; 49 HRM; Biosecurity. 


\section{Introduction}

Roses (Rosa spp.) belong to the family Rosaceae and are among the most popular flowering

52 shrubs in the United States with a total wholesale value of \$194 million (Paret, 2014). Roses are

53 cherished for their desirable aesthetics, landscaping and industrial products. In recent years, Rose

54 rosette disease (RRD) has become a devastating disease of roses causing economic losses to

55 ornamental nurseries in different parts of the United States including the state of Oklahoma

56 where RRD is commonly observed on both nursery and landscape roses. In 2012, RRD caused

57 severe losses to the Tulsa Municipal Rose Garden where thousands of rose plants were

58 eradicated (Stanley, 2013). RRD is a viral disease of commonly cultivated roses and the wild

59 rose Rosa multiflora. It was proposed to be caused by a newly characterized Rose rosette virus

60 (RRV), a ssRNA virus in the genus Emaravirus (Laney et al., 2011). RRD was first observed in

611940 in Manitoba, Canada (Conners, 1941). RRD is reported to be widespread in Kansas,

62 Oklahoma, Missouri and Arkansas, and has become widespread in north, south-central and

63 southeast parts of the United States (Christine, 2006, Epstein and Hill, 1995, Laney et al., 2011,

64 Windham et al., 2014a and Windham et al., 2014b). RRD has become a serious problem in these

65 states and a threat to the rose industry and landscape roses. RRD is transmitted by grafting and

66 the eriophyid mite Phyllocoptes fructiphilus (Amrine, 1988, Laney et al., 2011). The mites do

67 not fly but can passively move long distances by air currents and can spread to nearby roses

68 infecting rose plantings (Epstein and Hill, 1999, Windham et al., 2014a).

69 The symptoms of the disease are highly variable depending on the rose cultivar, and stage of 70 development of the plant. Symptoms may vary within the same cultivar at the same or different

71 locations (Epstein and Hill, 1995, 1999, Windham et al., 2014a, 2014b). RRD symptoms include

72 rapid elongation of lateral shoots: reddening of leaves and shoots, masses of shoot proliferation

73 (witches broom), excessive thorns, malformation, reduced flowering, and deformed buds and 
74 flowers (Amrine, 2002, Epstein and Hill, 1995) (Supplementary Fig. 1). RRD infected plants

75 become severely disfigured in one to three years after infection and are removed due to their

76 unpleasant appearance. Diagnosis of RRD in early stages is difficult and often confusing due to

77 symptoms resembling herbicide damage or caused by other plant viruses and/or pest problems.

78 Similar to other viral diseases, there is no chemical control for RRD. Once a rose plant becomes

79 infected, complete removal of plants is recommended as the plants are likely to harbor the vector

80 eriophyid mites. Reliable early detection of the disease is needed to prevent the spread of

81 infection to the healthy plants.

82 Laney et al. (2011) reported an endpoint RT-PCR primer sets for RRV detection. However,

83 the primers were used by other groups which had difficulty in detecting all RRV infected

84 samples (J. Olson; unpublished). Therefore, a reliable, accurate, sensitive and validated assay for detection of RRV is required. Moreover, rose tissues are rich in PCR inhibitors and frequently

86 produced false negatives; therefore, incorporation of amplification facilitators (like BSA and 87 PVP) in the reaction mix would be helpful to develop robust and validated protocol. Nucleic acid 88 based methods are rapid, reliable, have high specificity and discriminatory abilities and are more 89 sensitive than immunological methods (Dai et al., 2012, Arif et al., 2012, 2013b, 2014a and 90 Ouyang et al., 2013). Reverse transcription-polymerase chain reaction (RT-PCR) is considered a 91 sensitive and rapid method for detection of RNA viruses (Arif et al., 2014b). The sensitivity of 92 reverse transcription PCR (RT-PCR) depends importantly on the thermodynamics of the 93 oligonucleotide primers (Arif and Ochoa Corona, 2013). High sensitivity allows high capability 94 for detection of minute quantities of virus particles, leading to early detection of virus diseases 95 (Arif et al., 2014b). Other DNA amplification assays such as real time or quantitative PCR 96 (qPCR) offer increased sensitivity, accuracy and speed compared to end-point PCR for detection 
97 of target genes (Arif et al., 2014b, 2015). SYBR Green and TaqMan qPCR are the two most 98 popular formats of $\mathrm{qPCR}$ and are based on two different chemistries (Bustin, 2005). SYBR 99 Green assays use a fluorescent dye that intercalates with all double-stranded DNA, including 100 non-specific products that may be synthesized during the reaction, whereas, TaqMan assays use 101 a DNA probe that fluoresces only after the probe is cleaved during the amplification of a specific 102 product (Tomlinson et al., 2005). TaqMan assays offer highly specific detection and analysis of 103 the amplified products (Obrepalska-Steplowska et al., 2008). However, PCR probe-based 104 analyses are expensive, and often require considerable information about the targeted gene and 105 may be complex (VanGuilder et al., 2008). In contrast, SYBR Green assays are cost effective 106 and relatively simple to use (VanGuilder et al., 2008). High Resolution Melting (HRM) analyses 107 coupled to SYBR Green PCR exploits the SYBR-Green dye intercalates only in double-stranded 108 DNA and measures a decrease of fluorescence once the dsDNA start melting. The decreasing 109 fluorescence values are plotted against the temperature generating a melting curve unique and 110 characteristic of the amplified fragment that is characteristic of the targeted species or even 111 strains of the studied viral pathogen, facilitating discrimination from artifacts created by non112 specific products (Varga and James, 2005, Reed et al., 2007 and Winder et al., 2011). Both 113 SYBR Green qPCR and HRM curve analyses can be performed in a single tube. This method 114 allows detection and discrimination of the target simultaneously (Varga and James, 2005), and 115 has the advantage of monitoring the non-specific amplification.

116 This research reports the design of a single pair of diagnostic primer and demonstrates its 117 application in three RT-PCR chemistries: endpoint RT-PCR, TaqMan RT-qPCR, and SYBR 118 Green RT-qPCR assays. The SYBR Green RT-qPCR can also be combined with HRM curve 119 analyses for the detection of RRV. Moreover, a multi-target artificial positive control to include a 
120 probe target was also constructed for routine application in diagnostics. The application of a

121 single primer set with three different chemistries offer flexibility to operators in a diagnostic

122 network to adopt any of the three methods depending on the available resources in the

123 laboratory. The three developed methods will also assist epidemiological studies, breeding,

124 biosecurity, and management of the disease.

125

126

127

128

129

130

131

132

\section{Materials and Methods}

\subsection{Source of viruses and infected plant material}

Frozen plant tissue infected with RRV provided by the Plant Disease and Insect Diagnostic Laboratory (PDIDL), Oklahoma State University, Stillwater, was used as reference positive control. Other eleven virus lyophilized reference controls, including near-neighbor viruses and viruses commonly infecting roses, were used in an exclusivity panel: High plains virus, Maize stripe virus, Impatiens necrotic spot virus, Tomato spotted wilt virus, Groundnut ringspot virus, Tomato chlorotic spot virus, Apple mosaic virus, Arabis mosaic virus, Prunus necrotic ringspot virus, Tomato ringspot virus, and Tobacco mosaic virus were obtained from Agdia, Inc (Agdia, Elkhart, IN). A healthy Rosa 'Radrazz' (Knock Out ${ }^{\circledR}$ rose) from PDIDL was used as a source of healthy tissue for negative control. Infected plant material obtained from PDIDL was collected from eight states of the United States: Oklahoma, Indiana, Michigan, California, North Carolina, Virginia, New Jersey and Kentucky (Table 1). Samples consisted mostly of leaves. The majority of samples were symptomatic; however, a few asymptomatic plant samples were also included.

\subsection{Primer and probe design}

Twenty three sequences of RRV nucleocapsid gene p3 located in the RNA3 region were retrieved from NCBI GenBank database. The selected GenBank accessions were: HQ871944 and HQ891892-HQ891913 (Laney et al., 2011), aligned using CLUSTALX2 (Larkin et al., 2007) 
143 and examined for conserved regions. The last date NCBI GenBank database accessed was $17^{\text {th }}$ of 144 September, 2013. A primer pair RRV2F (Forward: 5'145 TGCTATAAGTCTCATtGGAAGAGAAA-3') and RRV2R (Reverse: 5'146 CCTATAGCTTCATCATTCCTCTTTG-3'), and the RRV probe-2 (5'147 TGCTAGAGACATTGGTACAACAAGCAA-3') were designed from a consensus sequence 148 generated after aligning the targeted gene to amplify a fragment of $104 \mathrm{bp}$. The web interface 149 application Primer3 (Rozen and Skaletsky, 2000) was used for primer design. The 150 thermodynamics, internal structures, and self-dimer formation of the primers were examined in151 silico using mFold (Zuker, 2003) following parameters described by Arif and Ochoa-Corona 152 (2013). The preliminary specificity of the primer set was assessed in-silico using BLASTn 153 (Altschul et al., 1990). The primers and probe 5'-6-carboxyfluorescein (FAM)-3' were 154 synthesized by IDT (Integrated DNA Technologies, Inc., Coralville, IA).

\subsection{Artificial positive control (APC)}

A synthetic, clonable and non-infectious multi-target artificial positive control (plasmid) was constructed as described by Caasi et al. (2013) for routine application in detection and diagnostics assays. The APC insert consists of a tandem of forward and reverse complement sequences of primers and probe targeting RRV, and amplified a 125 bp PCR amplicon using primer set RRV2F/2R. This APC also included primer sequences for other five major plant viruses used in our laboratory (GenBank accession number KP772215). The multi-target APC was artificially synthesized and ligated into a restriction site of pUC57 vector (GenScript USA Inc, Piscataway, NJ) which allows circularization and results in a clonable gene construct. A graphic description of the APC is shown in Figure 1.

\subsection{RNA isolation and cDNA synthesis}


Total RNA was isolated from symptomatic, and asymptomatic rose leaves, reference positive 167 control (RRV infected rose), a healthy Rosa 'Radrazz' Knock Out ${ }^{\circledR}$ (negative control), and 11

168 lyophilized reference control viruses. Approximately $100 \mathrm{mg}$ of the leaf tissue for each sample 169 was taken and macerated using a Mini-beadbeater ${ }^{\mathrm{TM}}$ (Biospec Products, Bartlesville, OK, ) for 40 170 s. Total RNA was extracted using the RNeasy Plant Mini kit (Qiagen, Valencia, CA) following 171 the manufacturer's instructions. For lyophilized reference control viruses, $450 \mu \mathrm{L}$ of Qiagen RLT 172 buffer plus $\beta$-Mercaptoethanol (as indicated by the manufacturer) was directly added to the 173 lyophilized tissue, mixed, transferred into $2 \mathrm{ml}$ eppendorf tubes, and vortexed for $30 \mathrm{~s}$. The total 174 RNA was subsequently extracted following the manufacturer's instructions. Four microliters of 175 extracted RNA was used to prepare cDNA. First-strand cDNA synthesis was performed using 176 random hexamer primers $(5 \mu \mathrm{M})$ and Moloney murine leukemia virus reverse transcriptase 177 (Promega, Madison, WI) according to the manufacturer's instructions and cDNA synthesis was 178 performed at $37{ }^{\circ} \mathrm{C}$ for $90 \mathrm{~min}$ and used within $24 \mathrm{~h}$. The quality of the RNA was confirmed 179 using the primers for plant internal control mitochondrial nad5 gene (Menzel et al., 2002).

\subsection{Gradient PCR}

The optimum annealing temperature $\left(T_{a}\right)$ of the RRV2F/2R primer set was determined 182 performing a gradient PCR with a $\mathrm{T}_{\mathrm{a}}$ range of 53.9 to $66^{\circ} \mathrm{C}$. The concentration of the APC DNA 183 (plasmid) used for this assay was $1 \mathrm{ng} /$ reaction. Twenty microliters of the amplified product was 184 visualized in $2 \%$ agarose gel electrophoresis in $1 \mathrm{X}$ TAE buffer $(\mathrm{pH}=8.0)$. Similarly, the Ta of 185 RRV2F/2R primer set was also tested using cDNA synthesized from a positive RRV infected 186 sample. For this assay $3 \mu \mathrm{l}$ of cDNA template was added to the PCR mix and tested within a $\mathrm{T}_{\mathrm{a}}$ 187 range of 54 to $64^{\circ} \mathrm{C}$. 
Preliminary endpoint RT-PCR was performed with positive RRV infected tissue (positive

190 control) with and without the addition of amplification facilitators (BSA: Bovine serum albumin, and PVP: Polyvinylpyrolidone; Dobhal et al., 2014b). Endpoint RT-PCR was performed in $20 \mu 1$ reaction volumes consisting of $10 \mu \mathrm{l}$ GoTaq Green Master Mix (Promega), $1 \mu \mathrm{l}$ of each RRV2F and RRV2R $(5 \mu \mathrm{M})$ primers, $3 \mu \mathrm{l}$ of cDNA template, $1.6 \mu \mathrm{l}$ of BSA (50 mg/ml; Ambion, Austin, TX), $2 \mu \mathrm{l}$ of 10\% PVP40 (Sigma-Aldrich, St. Louis, MO) and $1.4 \mu \mathrm{l}$ nuclease free water (Ambion). Two-step endpoint RT-PCR was performed in a thermal cycler (Biometra, Goettingen, Germany) and the cycling parameters were: initial denaturation of $94{ }^{\circ} \mathrm{C}$ for 3 min followed by 38 cycles of denaturation at $94{ }^{\circ} \mathrm{C}$ for $20 \mathrm{~s}$, annealing at $56^{\circ} \mathrm{C}$ for $30 \mathrm{~s}$, extension at $72{ }^{\circ} \mathrm{C}$ for $30 \mathrm{~s}$, and final extension at $72{ }^{\circ} \mathrm{C}$ for $3 \mathrm{~min}$. Positive (APC) and negative (healthy Rosa 'Radrazz' Knock Out ${ }^{\circledR}$ leaf tissue) controls were included. Twenty microliters of amplified RTPCR product was electrophoresed in $2 \%$ agarose gel in $1 \mathrm{X}$ TAE buffer. The amplified products were eluted from agarose gels using Quantum Prep Freeze'N Squeeze Spin Columns (Bio-Rad, Hercules, CA) and directly sequenced at the Oklahoma State University Recombinant DNA/Protein Core Facility using primers RRV2F and RRV2R

To test the specificity of the primer set RRV2F/2R with RRV, the primer set was tested with cDNA synthesized from reference positive control (infected RRV plant). The cross-reactivity of primer set RRV2F/2R was also tested with 11 reference control viruses in the exclusivity panel. The, healthy Knock Out ${ }^{\circledR}$ Rosa 'Radrazz' (negative control) was included in each assay. The samples negative for RRV specific RT-PCR were crosschecked for RNA quality using primers specific for plant mitochondrial nad5 gene (internal control; Menzel et al., 2002). The nad5 specific RT-PCR was performed by adding amplification facilitators (AFs) such as BSA and PVP into the reaction. 
2.7. PCR sensitivity assay using artificial positive control

The detection limit of the primer set RRV2F/2R was determined using a ten-fold serial dilution of plasmid DNA from $1 \mathrm{ng}$ to $1 \mathrm{fg}$. One microliter of each dilution was used as a template for PCR. PCR was performed in $20 \mu$ of reaction using reaction components and parameters described above. A negative control (non-template control: water) was also included in the assay. Twenty microliter of amplified product was electrophoresed using a $2 \%$ agarose gel in $1 \mathrm{X}$ TAE buffer.

2.8. Two-step endpoint RT-PCR sensitivity assay with infected plant tissue

A standard curve was prepared with ten-fold serially diluted plasmid DNA (APC) at concentrations of $1 \mathrm{ng}$ to $10 \mathrm{pg}$ using a real-time SYBR Green qPCR. The unknown RRV concentration in the cDNA (prepared from the infected positive plant tissue) was calculated from the APC standard curve as described by Arif et al. (2014b). The quantified cDNA was ten-fold serially diluted from $1 \mathrm{ng}$ to $1 \mathrm{fg}$. One microliter of each serially diluted cDNA was used as a template in endpoint RT-PCR following the conditions and parameters described above.

\subsection{Screening of field samples using two-step endpoint RT-PCR}

Thirty symptomatic and asymptomatic rose plant samples received from eight states of the United States were screened using endpoint two-step RT-PCR. Total RNA was individually extracted from each plant sample and a healthy Knock Out ${ }^{\circledR}$ Rosa 'Radrazz' leaves (negative control); cDNA was synthesized as described above, and $3 \mu 1$ of cDNA was used for endpoint RT-PCR. Twenty microliters of amplified RT-PCR product was used for electrophoresis. The amplified products were eluted from agarose gels using Quantum Prep Freeze'N Squeeze Spin Columns and directly sequenced as described earlier. The sequences were aligned and compared against sequences available in the GenBank nucleotide database using BLASTn. 
2.10. SYBR Green RT-qPCR, HRM analyses and screening of field samples

SYBR Green RT-qPCR and HRM analyses were performed using synthetic APC, a RRVinfected positive control sample, and 11 viruses included in the exclusivity panel. To standardize the method, preliminary experiments were performed with APC plasmid and reference positive control (RRV infected plant tissue) with and without the addition of AFs. SYBR Green RTqPCR amplification was carried out in $20 \mu \mathrm{l}$ reaction mixture containing $10 \mu \mathrm{l}$ of Platinum SYBR Green qPCR SuperMix-UDG (Invitrogen, Carlsbad, CA), $0.8 \mu \mathrm{l}(5 \mu \mathrm{M})$ of each RRV2F and RRV2R primers, $2 \mu \mathrm{l}$ of template cDNA, $1.6 \mu \mathrm{l}$ of BSA $(50 \mathrm{mg} / \mathrm{ml}), 2 \mu \mathrm{l}$ of $10 \%$ PVP40 and $2.8 \mu \mathrm{l}$ of nuclease-free water. Each reaction was performed in three replicates. The cycling parameters included two initial holds at $50{ }^{\circ} \mathrm{C}$ and $95{ }^{\circ} \mathrm{C}$ for $2 \mathrm{~min}$ each, followed by 40 cycles: $95{ }^{\circ} \mathrm{C}$ for $20 \mathrm{~s}$ and $54{ }^{\circ} \mathrm{C}$ for 45 s. The assays were performed in a Rotor-Gene 6000 thermocycler, and data analysis was done using Rotor-Gene 6000 series software 1.7 (Corbett Research, Sydney, Australia) with a manual cycle threshold (CT) of 0.1. The cDNA templates were amplified, and subsequently followed by a melting curve HRM protocol: a stepwise denaturation from 65 to $99{ }^{\circ} \mathrm{C}$ with $0.2{ }^{\circ} \mathrm{C}$ increments at each step, a default of $90 \mathrm{~s}$ of pre-melt conditioning on first step and a 2 s stop for each step afterwards was performed. Fluorescence data from melting curves were converted into melting profile charts using the Rotor-Gene 6000 series software 1.7 which plots the negative derivative of fluorescence $(-\mathrm{dF} / \mathrm{dT})$ vs. temperature (T). HRM curve, normalization and temperature shifts were also analyzed. To test the real-time SYBR Green RT-qPCR method with the infected field samples, eight out of the 30 samples were randomly selected and tested using the developed method. Positive and negative controls were included in each assay. The mean $T_{\mathrm{m}}$ was calculated for each sample and the standard deviation (SD) was determined. 
2.11. TaqMan RT-qPCR assay and screening of field samples

TaqMan RT-qPCR was performed with the 30 asymptomatic and symptomatic rose samples from eight different states, a reference positive control and 11 viruses in the exclusivity panel. TaqMan RT-qPCR was performed in a $20 \mu \mathrm{l}$ reaction containing $10 \mu \mathrm{l}$ of Platinum Quantitative PCR SuperMix-UDG (Invitrogen), $0.8 \mu \mathrm{l}(5 \mu \mathrm{M})$ of each RRV2F and RRV2R primers, $0.8 \mu \mathrm{l}(5$ $\mu \mathrm{M})$ of probe, $1.6 \mu \mathrm{l}$ of BSA $(50 \mathrm{mg} / \mathrm{ml}), 2 \mu \mathrm{l}$ of $10 \%$ PVP40, $2 \mu \mathrm{l}$ of template (cDNA in case of infected positive control or negative control or APC), and $2 \mu 1$ of nuclease-free water. Positive and negative controls were included in each assay and each reaction was performed in three replicates. Cycling parameters included two initial holds at $50{ }^{\circ} \mathrm{C}$ and $95{ }^{\circ} \mathrm{C}$ - each of 2 min; followed by 40 cycles: $95{ }^{\circ} \mathrm{C}$ for $20 \mathrm{~s}$ and $58{ }^{\circ} \mathrm{C}$ for $45 \mathrm{~s}$. The assays were performed in a RotorGene 6000 thermocycler, and the data analysis was done with a manual $C T$ of 0.1 using RotorGene 6000 series software 1.7. The mean of each set of replicates was calculated and the standard deviation was determined.

\section{Results}

3.1. In silico analyses of primers

The primer set RRV2F (Tm 59.8; G+C content 34.6\%; 3' complementarity $=2 ; 26 \mathrm{bp}$ ) and RRV2R (Tm 59.6; G+C content 40\%; 3' complementarity = 0; 25 bp), and the probe RRV2 (Tm 65.1; G+C content 40.7\%; 3' complementarity $=0 ; 27 \mathrm{bp}$ ), were obtained using Primer3 and were found specific for RRV after a pairwise alignment against the available GenBank nucleotide database using BLASTn. The calculated E-value of RRV2F, RRV2R and RRV2 probe were $1 \mathrm{e}-04,3 \mathrm{e}-04$ and 3e-05, respectively. BLASTn report of primer set RRV2F/2R showed $100 \%$ identity and $100 \%$ query coverage with all RRV accessions available in the GenBank nucleotide database. Primer set RRV2F/2R amplifies a conserved segment of $104 \mathrm{bp}$ 
281 from nucleotide 559 to 663 of the RRV nucleocapsid protein gene RNA3 (Accession number:

282 HQ871944.1). The $\Delta \mathrm{G}$ plot values calculated using mFold were $0.8,0.6$ and $1.0 \mathrm{kcal} / \mathrm{mol}$ for

283 RRV2F, RRV2R and RRV2 probe, respectively. The Tm difference between primers RRV2F

284 and RRV2R was $0.2{ }^{\circ} \mathrm{C}$ and between the primer set and the probe RRV2 were 5.3 and 5.5,

285 respectively.

286

287

288

289

290

291

292

293

294

295

296

297

298

299

300

301

302

\subsection{Gradient PCR and two-step endpoint RT-PCR}

Primer set RRV2F/2R amplified a diagnostic product from the predicted target of RRV p3 gene within a range of seven annealing temperatures $\left(\mathrm{T}_{\mathrm{a}}\right.$ ), from 53.9 ( circa $54{ }^{\circ} \mathrm{C}$ ) to $60{ }^{\circ} \mathrm{C}$. This result indicates primer set RRV2F/2R performed well in a broad range of $\mathrm{T}_{\mathrm{a}}$. The RT-PCR products were obtained within the expected amplification size, of $125 \mathrm{bp}$ from APC and $104 \mathrm{bp}$ from actual RRV (Fig. 2A and B). The primer set did not amplify products from the negative control (Rosa 'Radrazz' Knock Out ${ }^{\circledR}$ ) (Fig. 2B).

\subsection{Endpoint PCR and specificity of primers}

The RRV infected reference positive control (RRV infected rose tissue) did not amplify the expected product unless PCR AFs BSA and PVP40 were added to the PCR mixture (Supplementary Fig. 2). No cross-amplification was observed with the panel of eleven viruses (exclusivity panel). The cDNA has to be used preferably fresh within $24 \mathrm{~h}$ after the synthesis; otherwise a rapid degradation of cDNA templates leading to inconsistencies may be detected. This fact was observed to happen with knowingly positive infected samples.

\subsection{Sensitivity assay}

The detection limit of primer set RRV2F/2R after a ten-fold serial dilution of APC (plasmid) was 1 fg (Fig. 3A). A SYBR-Green RT-qPCR standard curve is shown in Figure 4A and B. 
Using the standard curve, the quantity of virus in the positive infected plant sample was found to be $8 \mathrm{pg}$ which was diluted to $1 \mathrm{pg}$ for starting concentration in endpoint RT-PCR. The detection limit of the RT-PCR to detect RRV from infected plant tissue was $1 \mathrm{fg}$ (equivalent to the 306 detection limit of the plasmid) with an expected amplification of $104 \mathrm{bp}$. No amplification was 307 observed with the negative plant control (Fig. 3B). The detection limit of endpoint RT-PCR to 308 detect the RRV from the infected host tissue and APC was equivalent.

\subsection{Screening of infected field samples with two-step endpoint RT-PCR}

All 30 asymptomatic and symptomatic rose samples tested positive (100\%) for RRV using 311 two-step endpoint RT-PCR. The expected PCR product of $104 \mathrm{bp}$ was visible, and no 312 amplification was observed with the negative control (healthy Knock Out ${ }^{\circledR}$ Rosa 'Radrazz') (Fig.

$3135 \mathrm{~A}$ and $\mathrm{B})$. Out of 30 samples, seven were randomly selected and sequence using both forward 314 and reverse primers RRV2F and RRV2R. The BLASTn alignment of obtained sequences 315 showed 99\% identity with twenty-three p3 RRV sequences available in the GenBank nucleotide 316 database.

\section{3.6. TaqMan RT-qPCR}

TaqMan RT-qPCR amplified the diagnostic target in the reference RRV positive control with an average $\mathrm{Ct}$ value of $28.76 \pm 0.36$ (mean $\pm \mathrm{SD}$ ). Amplification was not detected with the eleven viruses in the exclusivity panel (data not shown). This result confirmed that primer set RRV2F/2R and RRV2 probe were specific for the targeted virus fragment. It was also confirmed that assays carried out with AFs added to the PCR mixture consistently amplified samples that otherwise previously failed to amplify when AFs were not added. All 30 samples that tested

324 positive using endpoint RT PCR also tested positive using TaqMan RT-qPCR. The average $\mathrm{Ct}$ 325 values of the thirty field samples varied from $20.26_{(0.40)}$ to $36.45_{(1.35)}$ (Table 1). A graphic 
326 representation of seven randomly selected samples with the positive and negative control is

327 shown in Figure 6.

328

329

330

331

332

333

334

335

336

337

338

339

340

341

342

343

344

345

346

347

348

\subsection{SYBR-Green RT-qPCR and HRM analyses}

Positive amplification by SYBR-Green RT-qPCR and HRM of the expected RRV target was only consistently possible after the addition of AFs. The HRM Tm was $75.7 \pm 0.03{ }^{\circ} \mathrm{C}$ (mean \pm SD, n=3) (data not shown). The SYBR-Green RT-qPCR followed by HRM with AFs allowed amplification of the targeted diagnostic product of RRV reference positive control with a distinct Tm of $75.6 \pm 0.1{ }^{\circ} \mathrm{C}($ mean $\pm \mathrm{SD}, \mathrm{n}=6)$. The melting curve profile of the RRV diagnostic product from APC has a different $T \mathrm{~m}$ of $78.85 \pm 0.06{ }^{\circ} \mathrm{C}$ (mean $\pm \mathrm{SD}, \mathrm{n}=9$ ) as expected. No amplification or HRM curve was obtained with healthy Knock Out ${ }^{\circledR}$ Rosa 'Radrazz' (negative control) (Fig. 7). Furthermore, no amplification was observed with cDNA from viruses in the exclusivity panel. The eight randomly selected samples out of the 30 asymptomatic and symptomatic samples also tested positive for RRV by SYBR-Green RT-qPCR. The average Ct

values of those eight samples are shown in Table 1 and a $C_{T}$ plot of five samples is shown in Figure 8A. The HRM curve of the five infected plant samples is shown in Figure 8B. The HRM temperatures were $75.7 \pm 0.04^{\circ} \mathrm{C}, 75.7 \pm 0.02^{\circ} \mathrm{C}, 75.7 \pm 0.03^{\circ} \mathrm{C}, 75.7 \pm 0.02^{\circ} \mathrm{C}$ and $75.7 \pm 0.0^{\circ} \mathrm{C}$ (mean $\pm \mathrm{SD}, \mathrm{n}=3$ ) for R4, R11, R14, R29 and R30 samples, respectively.

\section{Discussion}

This study describes and demonstrates the development of a single primer set for sensitive, reliable and highly specific detection of RRV by endpoint RT-PCR, TaqMan RT-qPCR, and SYBR-Green RT-qPCR which can be coupled to HRM analyses.

RRD is a major problem for rose growers in many parts of the United States and is causing dramatic losses in yield and quality of the roses. Since early symptoms of RRD are difficult to 
349 diagnose, RRD has spread due to failure in early detection to make timely control measures.

350 Moreover, Rosa spp. tissues are rich in inhibitors that cause inconsistent results when large

351 numbers of specimens are routinely tested. These inconsistencies also raised concerns about

352 whether all RRV isolates are being detected. Therefore, a sensitive and reliable diagnostic

353 method considering these two important concerns was needed.

354 In general, PCR based detection methods are more sensitive, reliable and accurate for 355 detection and discrimination of the pathogens than immunological methods, if the primers are 356 designed from signature regions of a targeted gene (Arif et al., 2013 and Arif et al., 2014b). RT357 PCR is one of the most popular, efficient, accurate and reliable method for the detection of RNA 358 viruses. A detection endpoint RT-PCR was reported by Laney et al. (2011) by the time RRV 359 genomic organization was reported. This research reports and validates primers designed to 360 perform consistently in endpoint RT-PCR and two RT-qPCR based detection methods cross 361 validated with an exclusivity panel of eleven viruses and demonstrated its application testing 362 field samples. The design and development of this new set of primers focused over the consensus 363 region of the nucleocapsid gene p3 located in the RNA3 of all RRV isolates submitted to the 364 NCBI GenBank to date. The primers were further tested in silico for their thermodynamics 365 features following parameters outlined by Arif and Ochoa Corona (2013). The primers did not 366 show complex 3' self-complementary secondary structures. The BLASTn results of primer set 367 RRV2F/2R showed $100 \%$ similarity with the p3 gene of RRV and twenty three p3 sequences of 368 RRV in GenBank.

369 RT-PCR requires the extraction of RNA from the plant tissue. RNA isolation from infected 370 rose plant tissue is often complicated due to abundance of phenolic compounds, carbohydrates, 371 pigments, and other unknown compounds. These compounds may play an inhibitory role 
372 interacting irreversibly with nucleic acid and proteins leading to oxidation and degradation

373 reducing the quality of RNA and subsequent analysis (Salzman et al., 1999). It was observed that

374 RRV was not consistently detected from infected rose tissue if AFs were not added. This could

375 have been caused by inhibitors precipitating with viral RNA during the extraction procedure. The

376 addition of BSA and PVP40 as AFs to the PCR mix improved consistently the amplification of

$377104 \mathrm{bp}$ diagnostic product. The incorporation of AFs in the PCR mix was adapted from a

378 previously reported method by Dobhal et al. (2014b), who demonstrated the incorporation of

379 AFs in PCR mixture were able to relieve the inhibitory effect of inhibitors present in different

380 sample matrices. The incorporation of AFs did not have a negative effect on the specificity of the

381 primers as no cross-reaction was observed with the cDNA of viruses in the exclusivity panel and

382 negative control (healthy tissue of Knock Out ${ }^{\circledR}$ Rosa 'Radrazz'). Positive amplification was

383 observed only with RRV infected samples, which demonstrated the three methods are specific

384 for detection of RRV. Further sequencing of the amplified product using the primers RRV2F/2R 385 confirmed the RRV identity.

386 The developed endpoint RT-PCR was further assessed using symptomatic and asymptomatic 387 plant samples from eight different locations in the United States. Endpoint RT-PCR was able to 388 detect the infection in all samples tested. No amplification was observed with cDNA from 389 healthy tissue of Knock Out ${ }^{\circledR}$ Rosa 'Radrazz' (negative control) showing the RRV primer set 390 RRV2F/2R was not reactive with the host plant. Endpoint RT-PCR was also able to detect RRV 391 in asymptomatic plant samples three months before to the onset of visual symptoms. Samples 392 testing negative for the RRV, tested positive for nad5 gene used as an internal control confirming 393 these samples were true negatives. 
Furthermore, a qPCR standard curve was made with a known APC concentration and the 395 unknown concentration of RRV cDNA synthesized from infected plant tissue RNA was plotted and calculated as described by Arif et al. (2014b). Primer set RRV2F/2R detected RRV at a 397 concentration down to $1 \mathrm{fg}$ in infected plant tissue, similar to the detection limit observed when 398 using APC.

399 The size of the amplified product and RRV2F/2R thermodynamics allows these set of oligos 400 to be compatible with two real-time RT-qPCR chemistries. In fact, all 30 field samples tested 401 positive to RRV demonstrating primers compatibility with TaqMan RT-qPCR. No contradictory 402 results or cross amplifications were observed after the incorporation of AFs in the Taqman RT403 qPCR assays. Primer set RRV2F/2R was also compatible with SYBR Green RT-qPCR. SYBR404 Green qPCR chemistry is a less expensive alternative to TaqMan (Arif et al., 2014b).

405 A HRM curve analyses was also demonstrated to work in conjunction with SYBR-Green RT406 qPCR. HRM coupled to RT-qPCR allows simultaneous detection and discrimination of variants 407 within single or multiple PCR products (Winder et al., 2011). As expected the $T_{m}$ of the field 408 samples $\left(75.7 \pm 0.04^{\circ} \mathrm{C}\right)$ were similar to the $T_{\mathrm{m}}$ of RRV reference positive control $\left(75.6 \pm 0.1^{\circ} \mathrm{C}\right)$. 409 The $T_{\mathrm{m}}$ of the APC $\left(78.85 \pm 0.06^{\circ} \mathrm{C}\right)$ also showed a characteristic melting profile different from 410 positive RRV infected plant tissue, which allows discrimination of positive samples and the 411 APC. The HRM analyses also discriminate false negatives that might had generated by cross412 contamination (Winder et al., 2011). No HRM profiles were generated from any of the 11 viruses 413 in the exclusivity panel.

414 A consistent and reliable single primer pair based detection method compatible with three 415 different RT-PCR chemistries is reported. The selection of the method to be used will depend on 416 the end user's preferences, laboratory capabilities or diagnostic strategy. The three tested 
417 methods are simple, sensitive, reproducible, and have application in detection and discrimination 418 of RRV. RRV detection by RT-PCR can be challenging due to presence of the inhibitory 419 compounds in rose tissue especially when the virus is present in low titer. The use of AFs in the 420 PCR mixture reduces the risk of false negatives. Furthermore, during this study we observed that 421 cDNA synthesized from RNA stored at $-80{ }^{\circ} \mathrm{C}$ for more than a month may fail to amplify even 422 when AFs were added. Therefore, all assays were performed either with freshly prepared RNA 423 and no older than one week. Best results are obtained when cDNA is used freshly extracted

424 before experimentation and used immediately with any of the reported RT-PCR chemistries. 425 These methods have application in epidemiological studies, biosecurity, as well as rapid 426 screening of the asymptomatic plants in certification and breeding programs.

\section{Acknowledgements}

428 We thank Dr. Ulrich Melcher and Dr. Trenna Blagden (Oklahoma State University) for 429 reviewing the manuscript. This work was funded by Oklahoma Agricultural Experiment Station 430 (OKL02773), the American Floral Endowment, and USDA's National Institute of Food and 431 Agriculture (NIFA) Specialty Crop Research Initiative project, "Combating Rose Rosette 432 Disease: Short Term and Long Term Approaches” (2014-51181-22644/SCRI). The mention of 433 trade names or commercial products does not imply recommendation or endorsement by 434 Oklahoma State University.

435 No conflict of interest exists.

\section{References}

437 Altschul, S.F., Gish, W., Miller, W., Myers, E.W., Lipman, D.J., 1990. Basic local alignment 438 search tool. J. Mol. Biol. 215, 403-41. 
Amrine, J., Hindal, D., Stany, T., Williams, R., Coffman, C., 1988. Transmission of the rose rosette disease agent to Rosa multiflora Thunb. by Phyllocoptes fructiphilus Keifer (Acari: Eriophyidae). Entomol News. 99, 239-252. Arif, M., Ochoa-Corona, F.M., Opit, G., Li, Z.H., Kučerová, Z., Stejskal, V., Yang, Q.Q., 2012. PCR and isothermal-based molecular identification of the stored-product psocid pest Lepinotus reticulatus (Psocoptera: Trogiidae). J Stored Prod Res. 49, 184-188. sequences with optimal and sub-optimal primers to increase PCR yields and sensitivity. Mol. Biotechnol. 55, 17-26. rapid, sensitive and field deployable Razor Ex biodetection system and qPCR assay for detection of Phymatotrichopsis omnivora using multiple gene targets. Appl. Environ. Arif, M., Dobhal, S., Garrido, P.A., Orquera, G. K., Espíndola, A.S., Young, C.A., OchoaCorona, F.M., Marek, S.M., and Garzón, C.D., 2014a. Highly sensitive end-point PCR and Microbiol. 79, 2312-2320.

Arif, M., Aguilar-Moreno, G.S., Wayadande, A., Fletcher, J., Ochoa-Corona, F.M., $2014 b$. Primer modification improves rapid and sensitive in vitro and field deployable assays for 
Arif, M., Opit, G., Mendoza-Yerbafria, Dobhal, S., Li, Z., Kucerova, Z., Ochoa-Corona,

460 F.M., 2015. Array of synthetic oligonucleotides to generate unique multi-target artificial 461 positive controls and molecular probe-based discrimination of Liposcelis species. PloS One. 462 10(6):e0129810.doi:10.1371/journal.pone.0129810.

463 Bustin, S.A., 2005. Real-time, fluorescence-based quantitative PCR: a snapshot of current $464 \quad$ procedures and preferences. Expert Rev. Mol. Diagn. 5, 493- 498. multi-target, non-infectious and clonable artificial positive control for routine PCR-based assays. J. Microbiol. Methods. 95, 229-234.

Christine, J.L., 2006. The biology of Rosa multiflora (Rosaceae) and two of its biotic mortality factors. Retrospective Theses and Dissertations. Paper 1267. Available at: $471 \quad$ September 2014.

472 Conners, L., 1941. Twentieth annual report of the Canadian plant report survey 1940, pp 98.

473 Crowe, F.J., 1983. Witches' broom of rose: A new outbreak in several central states. Plant 474 Dis. $67,544-546$.

475 Dai, J., Cheng, J., Huang, T., Zheng, X., Wu, Y., 2012. A multiplex reverse transcription 476 PCR assay for simultaneous detection of five tobacco viruses in tobacco plants. J. Virol 477 Methods. 183, 57-62. 
studying multiple infections of five major plant viruses infecting ornamental plants in nursery environments. Ann. App. Biol. doi:10.1111/aab.12182.

482

483

484

485

486

487

Dobhal, S., Zhang, G., Rohla, C., Smith, M.W., Ma, L.M., 2014b. A simple, rapid, costeffective and sensitive method for detection of Salmonella in environmental and pecan samples. J. Appl Microbiol. doi:10.1111/jam.12583.

Epstein, A., Hill, J., 1995. The biology of rose rosette disease: a mite associated disease of uncertain etiology. J. Phytopathol. 143, 353-360.

Epstein, A.H., Hill, J. H., 1999. Status of rose rosette disease as a biological control for multiflora rose. Plant Dis. 83:92-101.

Laney, A.G., Keller, K.E., Martin, R.R., Tzanetakis, I.E., 2011. A discovery 70 years in the making: characterization of the Rose rosette virus. J. Gen Virol. 92, 1727-1732.

Larkin, M.A., Blackshields, G., Brown, N.P., Chenna, R., McGettigan, P.A., McWilliam, H., Valentin, F., Wallace, I.M., Wilm, A., Lopez, R., Thompson, J.D., Gibson, T.J., Higgins, D.G., 2007. ClustalW2 and clustalX version 2. Bioinformatics. 23, 2947-2948.

Menzel, W., Jelkmann, W., Maiss, E., 2002. Detection of four apple viruses by multiplex RT-PCR assays with coamplification of plant mRNA as internal control. J. Virol. Methods. 99, 81-92

Paret, M., 2014. Rose Rosette Virus, a devastating disease on Roses, found in Florida. Available at: http://liberty.ifas.ufl.edu/newsletters/2014/03/25/rose-rosette-virus-adevastating-disease-on-roses-found-in-florida/. Accessed 1 September 2014. 
Rozen, S., Skaletsky, H.J., 2000. Primer3 on the WWW for general users and for biologist programmers, in Krawetz S., Misener, S. (Eds.), Bioinformatics Methods and Protocols: Methods in Molecular Biology. Totowa, NJ, Humana Press: USA. pp. 365-386.

Salzman, R.A., Fujita, T., Zhu-Salzman, K., Hasegawa, P.M., Bressan, R.A., 1999. An improved RNA isolation method for plant tissues containing high level of phenolic compounds or carbohydrates. Plant Mol Biol Rep. 17, 11-17. at: http://www.tulsaworld.com/homepagelatest/rose-disease-killing-hundreds-of-bushes-attulsa-rose-garden/article_ad10e378-31f7-11e3-9e39-001a4bcf6878.html. Accessed 1 September, 2014.

Obrepalska-Steplowska, A., Nowaczyk, K., Holysz, M., Gawlak, M., Nawrot, J., 2008. Molecular techniques for the detection of granary weevil (Sitophilus granarius L.) in wheat and flour. Food Additives \& Contaminants. Part A, Chemistry, Analysis, Control, Exposure \& Risk Assessment, 25(10), 1179-1188.

Ouyang, P., Arif, M., Fletcher, J., Melcher, U., Ochoa-Corona, F.M., 2013. Enhanced simple and efficient molecular diagnostics. Pharmacogenomics. 8(6), 597-608. 
Tomlinson, J.A., Boonham, N., Hughes, K.J.D., Griffen, R.L., Barker, I., 2005. On-site DNA

522 extraction and real-time PCR for detection of Phytophthora ramorum in the field. Appl.

$523 \quad$ Environ. Microbiol. 71, 6702-6710.

524 VanGuilder, H.D., Vrana, K.E., Freeman, W.M., 2008. Twenty-five years of quantitative 525 PCR for gene expression analysis. BioTechniques. 44(5), 619-626.

526 Varga, A., James, D., 2005. Detection and differentiation of Plum pox virus using real-time 527 multiplex PCR with SYBR Green and melting curve analysis: a rapid method for strain 528 typing. J. Virol. Methods. 123, 213-220.

529 Winder, L., Phillips, C., Richards, N., Ochoa-Corona, F., Hardwick S., Vink C. J., Goldson 530 S., 2011. Evaluation of DNA melting analysis as a tool for species identification. Methods in $531 \quad$ Ecology and Evolution. 2, 312-320.

532 Windham, M., Windham, A., Hale, F., 2014a. Observations on Rose rosette disease. 533 http://www.newenglandgrows.org/pdfs/ho_WindhamRoseRosette.pdf. $\quad$ Accessed 1 $534 \quad$ September, 2014.

Windham, M., Windham, A., Hale, F., Hitch, W., 2014b. Rose Rosette: identification and management. $\quad$ SNA research Conference, 59:143-146. 537 http://www.sna.org/Resources/Documents/14resprosec06.pdf. Accessed 1 September, 2014.

538 Zuker, M., 2003. Mfold web server for nucleic acid folding and hybridization prediction. $539 \quad$ Nucleic Acids Res. 31, 3406-3415. 


\section{$542 \quad$ Figure Legends}

543 Figure 1: The artificial positive control (APC). Custom synthesized tandem of forward and 544 reverse complement primer sequences ligated into a multiple cloning site of pUC57. Each PCR 545 product produces a unique sequence for each target also useful in product verification and quality 546 control. The APC also contains primer sequences for five other target viruses.

547 Figure 2: Gradient end point PCR and two steps RT-PCR using primer set RRV2F/2R. 548 Annealing temperature (Ta) ranged from (A) 53.9 to $66^{\circ} \mathrm{C}$ using the APC (plasmid DNA), and 549 (B) 54 to $64{ }^{\circ} \mathrm{C}$ using cDNA from infected tissue. Lane M, 50 bp DNA ladder; lane N, non550 template control (NTC; water).

551 Figure 3: Sensitivity assays. (A) PCR sensitivity assay using ten-fold serially diluted APC 552 (plasmid DNA) starting from $1 \mathrm{ng}$ to $1 \mathrm{fg}$. Lane M, $50 \mathrm{bp}$ ladder; lane 1, $1 \mathrm{ng}$; lane 2, $100 \mathrm{pg}$; 553 lane 3, $10 \mathrm{pg}$; lane 4, $1 \mathrm{pg}$; lane 5, $100 \mathrm{fg}$; lane 6, $10 \mathrm{fg}$; lane 7, $1 \mathrm{fg}$; lane N, non-template control 554 (NTC, water). (B) RT-PCR sensitivity assay using ten-fold serially diluted infected host cDNA 555 from Rose rosette virus infected tissue. Lane M, 50 bp ladder; lane 1, 1 pg; lane 2, 100 fg; lane 3, $55610 \mathrm{fg}$; lane 4, $1 \mathrm{fg}$; lane N, healthy plant control (negative control, healthy Knock Out ${ }^{\circledR}$ Rosa 557 'Radrazz').

558 Figure 4: (A, B) SYBR Green qPCR standard curve/graph generated using ten-fold serial 559 dilution of APC (plasmid DNA) for quantification of unknown cDNA (prepared from infected 560 host tissue). $\mathrm{R} 2$ is linear correlation coefficient, $\mathrm{Y}$ is the slope, and Ex is the reaction efficiency.

561 Each reaction was performed in three replicates. $\mathrm{X}$ axis represents the number of cycles, and $\mathrm{Y}$ 562 axis is normalized fluorescence. 
563 Figure 5: Screening of Rose samples (30) collected from eight states of the United States using 564 two steps endpoint RT-PCR. (A, B) Lane M, 50 bp ladder; lane P, Positive control (APC), lanes 565 1-30, Asymptomatic and symptomatic rose samples R1-R30 as indicated in Table 1; lane N, 566 Healthy plant sample (negative control, healthy Knock Out ${ }^{\circledR}$ Rosa 'Radrazz').

567 Figure 6: TaqMan RT-qPCR assay using infected field samples. Positive control, Infected Rose 568 rosette virus plant; R7, 201301191; R12, 201301166; R9, 2013002284; R13, 201301097; R3, 569 201301118; R6, 201302232; R5, 201300232 (Table 1); Negative control, Healthy plant sample 570 (healthy Knock Out ${ }^{\circledR}$ Rosa 'Radrazz'); NTC, Non-template control. Each reaction was 571 performed in three replicates.

572 Figure 7: $\mathrm{HRM}$ analyses showing the melting profile of $\mathrm{APC}\left(T_{\mathrm{m}}=78.85 \pm 0.06{ }^{\circ} \mathrm{C}\right.$, mean $\pm \mathrm{SD}$, $573 \mathrm{n}=9)$ and positive RRV infected sample $\left(T_{\mathrm{m}}=75.6 \pm 0.1^{\circ} \mathrm{C}\right.$, mean $\left.\pm \mathrm{SD}, \mathrm{n}=6\right)$ amplified using 574 RRV2F/2R primer set (Arrows indicate the $T_{\mathrm{m}}$ ). Only the plant sample infected with RRV is 575 amplified.

576 Figure 8: SYBR-Green RT-qPCR and HRM curve chart of randomly selected infected field 577 samples. (A) SYBR-Green RT-qPCR assay (B) Melt peak chart for cDNA amplified using RRV 578 specific primer set. Positive control, Plasmid; R29, 1; R30, 2; R4, 201301016; R14, 201301704; 579 R11, 201302234; NTC, Non-template control. Each reaction was performed in three replicates.

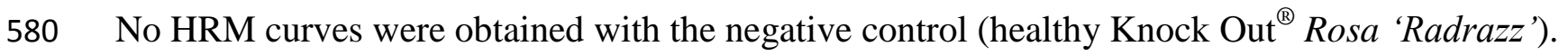

\section{Supplementary Figures Legend}

582 Supplementary Figure 1: Symptoms of Rose rosette disease on landscape roses. (A, B) Infected 583 plant showing reddening of stems, thin elongated and malformed leaves with increased number 584 of prickles, (C, D) Distorted flower buds on rose infected with the RRV often leading to the 
585 failure of bud to open, (E) Abnormal red discoloration of leaves and excessive prickles on 586 thickened stem, (F) Rose rosette disease within a bed of asymptomatic plants. Red color and 587 witches broom is noted.

588 Supplementary Figure 2: Endpoint RT-PCR using primer set RRV2F/2R with and without the 589 incorporation of amplification facilitators (AFs) in the PCR mix. Lane M, 50 bp DNA ladder; 590 lane N, non-template control (NTC; water). 
Table 1: RT-PCR and RT-qPCR detection of Rose Rosette virus (RRV) from symptomatic and asymptomatic Rosa spp. collected from different states of the United States

\begin{tabular}{|c|c|c|c|c|c|c|}
\hline $\begin{array}{c}\text { Sample code used in the } \\
\text { study }\end{array}$ & Original sample code & Host* & Location & $\begin{array}{c}\text { RT-PCR } \\
\text { (RRV) }\end{array}$ & $\begin{array}{c}\text { Average } \mathrm{C}_{\mathrm{T}(\mathrm{SD})} \text { values } \\
\text { using TaqMan } \mathrm{RT} \text { - } \\
\text { qPCR }\end{array}$ & $\begin{array}{c}\text { Average } \mathrm{C}_{\mathrm{T}(\mathrm{SD})} \\
\text { values using } \mathrm{SYBR}- \\
\text { Green } \mathrm{RT} \text {-qPCR }\end{array}$ \\
\hline $\mathrm{R} 1$ & 201301541 & Rose (Pink Home Run) & Oklahoma & + & $33.16_{(0.09)}$ & $35.68_{(0.51)}$ \\
\hline $\mathrm{R} 2$ & 201301202 & Rose & Oklahoma & + & $30.58_{(0.48)}$ & $28.40_{(1.12)}$ \\
\hline R3 & 201301118 & Rose & Oklahoma & + & $29.38_{(0.19)}$ & $\mathrm{x}$ \\
\hline $\mathrm{R} 4$ & 201301016 & Rose (Pink Knock Out ${ }^{\circledR}$ ) & Oklahoma & + & $23.84_{(0.54)}$ & $23.63_{(0.48)}$ \\
\hline R5 & 201300232 & Rose & Oklahoma & + & $34.13_{(0.09)}$ & $\mathrm{x}$ \\
\hline R6 & 201302232 & Rose (Chris Evert) & Oklahoma & + & $31.55_{(0.32)}$ & $\mathrm{x}$ \\
\hline R7 & 201301191 & Rose & Indiana & + & $21.94_{(0.14)}$ & $\mathrm{x}$ \\
\hline R8 & 201301192 & Rose & Indiana & + & $30.61_{(0.18)}$ & $\mathrm{x}$ \\
\hline R9 & 201302284 & Rose & Michigan & + & $27.51_{(0.17)}$ & $\mathrm{x}$ \\
\hline $\mathrm{R} 10$ & 201301814 & Rose (Red Velvet) & California & + & $32.15_{(0.21)}$ & $\mathrm{x}$ \\
\hline $\mathrm{R} 11$ & 201302234 & Rose & North Carolina & + & $34.53_{(0.76)}$ & $38.15_{(0.33)}$ \\
\hline $\mathrm{R} 12$ & 201301166 & Rose (Rosy-Red Robin Hood ) & Indiana & + & $24.1_{(1.48)}$ & $\mathrm{x}$ \\
\hline $\mathrm{R} 13$ & 201301097 & Rose & Virginia & + & $28.91_{(0.25)}$ & $\mathrm{x}$ \\
\hline $\mathrm{R} 14$ & 201301704 & Rose & New Jersey & + & $26.53_{(0.07)}$ & $26.83_{(1.67)}$ \\
\hline $\mathrm{R} 15$ & 201301815 & Rose (South Africa origin) & California & + & $36.45_{(1.35)}$ & $35.89_{(0.97)}$ \\
\hline $\mathrm{R} 16$ & 201301105 & Rose & North Carolina & + & $30.84_{(0.30)}$ & $\mathrm{x}$ \\
\hline $\mathrm{R} 17$ & 201301490 & Rose & Virginia & + & $27.63_{(0.28)}$ & $\mathrm{x}$ \\
\hline $\mathrm{R} 18$ & 201301719 & Rose $\left(\right.$ Knock Out $\left.^{\circledR}\right)$ & Kentucky & + & $25.46_{(0.18)}$ & $\mathrm{x}$ \\
\hline R19 & 201301219 & Rose & Michigan & + & $28.65_{(0.21)}$ & $\mathrm{x}$ \\
\hline $\mathrm{R} 20$ & 201301104 & Rose & North Carolina & + & $26.88_{(0.17)}$ & $\mathrm{x}$ \\
\hline $\mathrm{R} 21$ & 201301102 & Rose & North Carolina & + & $26.82_{(0.26)}$ & $\mathrm{x}$ \\
\hline $\mathrm{R} 22$ & 201301716 & Rose & Virginia & + & $32.33_{(0.57)}$ & $\mathrm{x}$ \\
\hline $\mathrm{R} 23$ & 201300219 & Rose & Oklahoma & + & $27.54_{(0.29)}$ & $\mathrm{x}$ \\
\hline $\mathrm{R} 24$ & 201301755 & Rose (Knock Out $\left.{ }^{\circledR}\right)$ & Kentucky & + & $34.49_{(0.61)}$ & $\mathrm{x}$ \\
\hline $\mathrm{R} 25$ & 201301754 & Rose $\left(\right.$ Knock Out $\left.{ }^{\circledR}\right)$ & Kentucky & + & $36.11_{(0.61)}$ & $\mathrm{x}$ \\
\hline $\mathrm{R} 26$ & 201300222 & Rose & Oklahoma & + & $33.75_{(0.58)}$ & $\mathrm{x}$ \\
\hline $\mathrm{R} 27$ & 201300220 & Rose & Oklahoma & + & $31.36_{(0.37)}$ & $\mathrm{x}$ \\
\hline $\mathrm{R} 28$ & 201300218 & Rose (Double Knock Out ${ }^{\circledR}$ ) & Oklahoma & + & $29.57_{(0.09)}$ & $\mathrm{x}$ \\
\hline $\mathrm{R} 29$ & 1 & Rose & Oklahoma & + & $20.26_{(0.40)}$ & $19.53_{(0.22)}$ \\
\hline $\mathrm{R} 30$ & 2 & Rose & Oklahoma & + & $20.43_{(0.19)}$ & $19.95_{(1.49)}$ \\
\hline Positive Reference control & 201300956 & Rose & Oklahoma & + & $23.61_{(0.15)}$ & $28.4_{(1.12)}$ \\
\hline Negative control & $\mathrm{NC}$ & Rose (Healthy Knock Out ${ }^{\circledR}$ ) & Oklahoma & - & - & - \\
\hline Non-template control & NTC & Nuclease free water & Ambion, Austin, TX & - & - & - \\
\hline
\end{tabular}


$\mathrm{C}_{\mathrm{T}}$ values are average of 3 replicates. $\mathrm{SD}=$ Standard deviation of 3 replicates. $+=$ samples tested positive. $\mathrm{X}=$ samples not tested. $-=$ negative. The assays were performed using cDNA prepared from RNA extracted from the leaf tissue of asymptomatic and symptomatic plant samples (Roses).

* Cultivar was unknown unless otherwise noted in brackets 
FIGURES

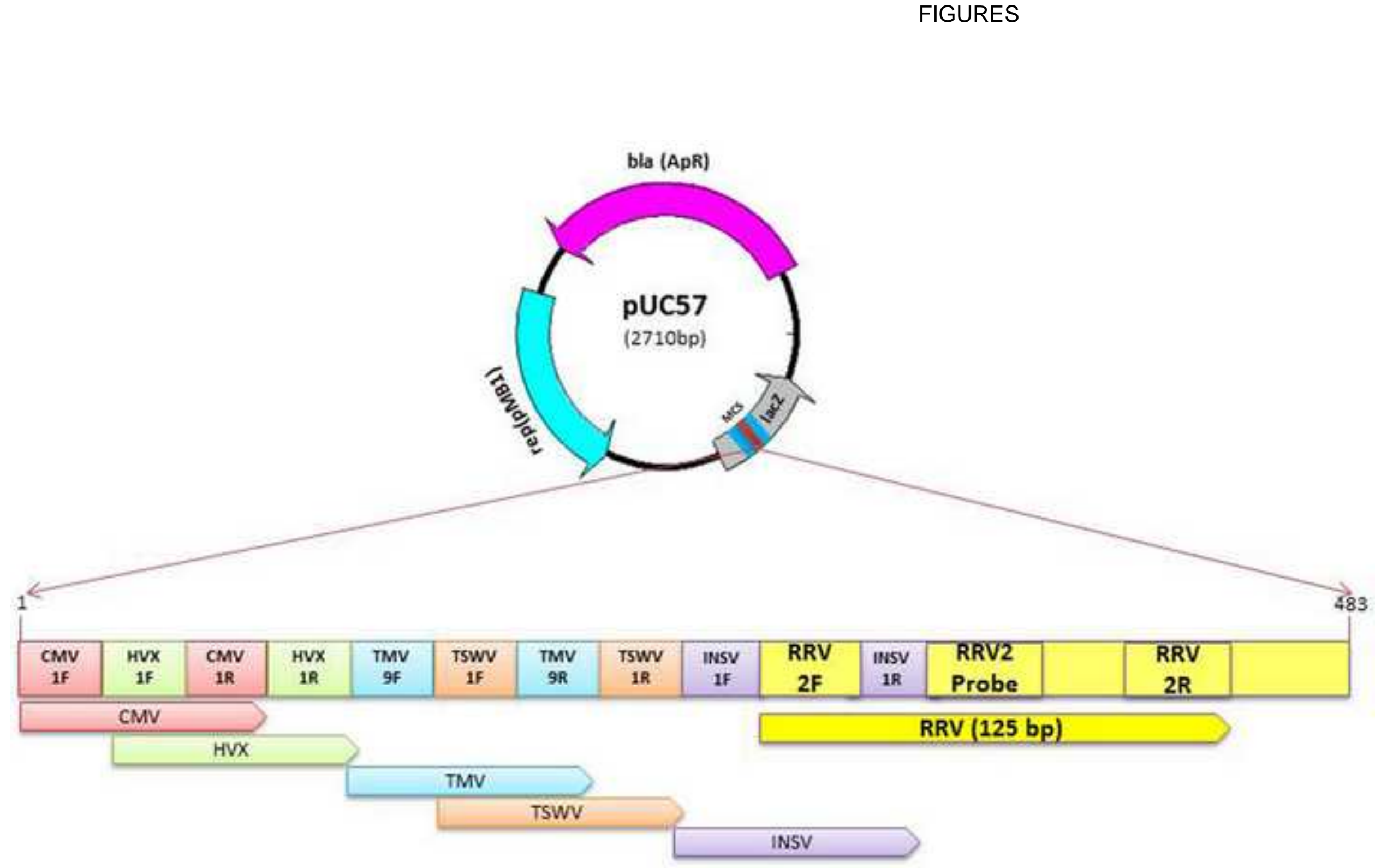

83. 

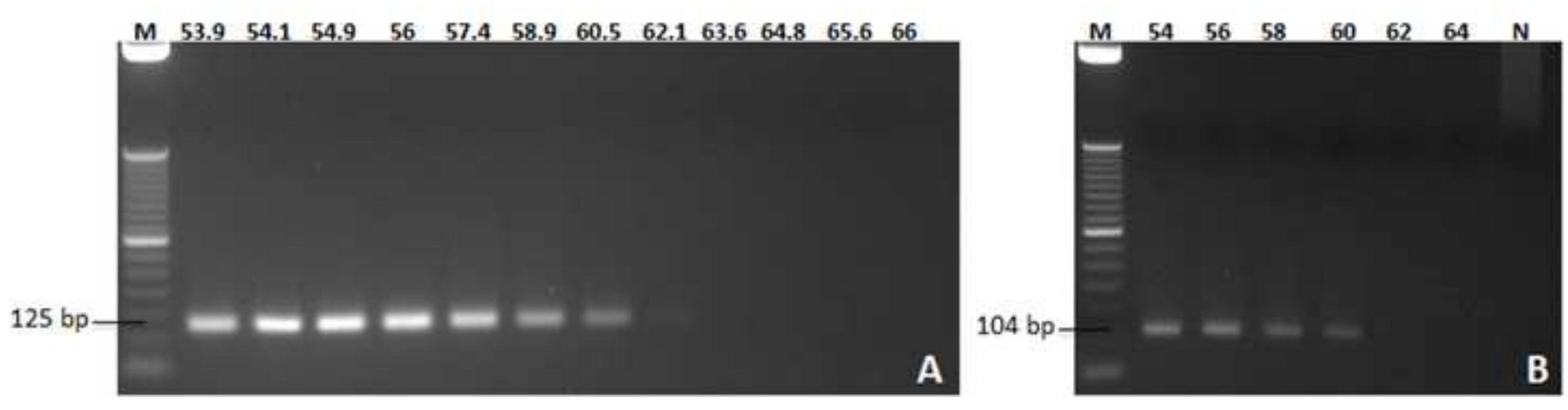

Figure 2

$\begin{array}{llllllll}58.9 & 60.5 & 62.1 & 63.6 & 64.8 & 65.6 & 66\end{array}$

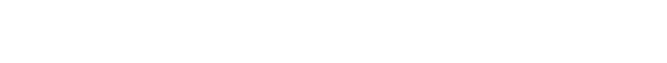

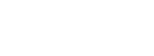
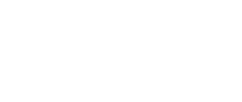

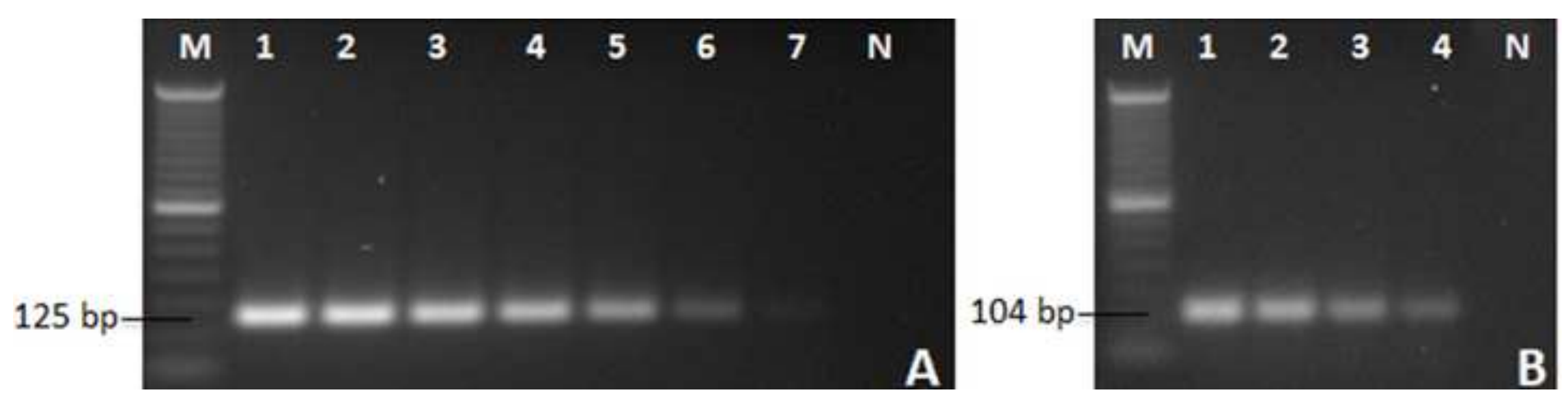

Figure

B 


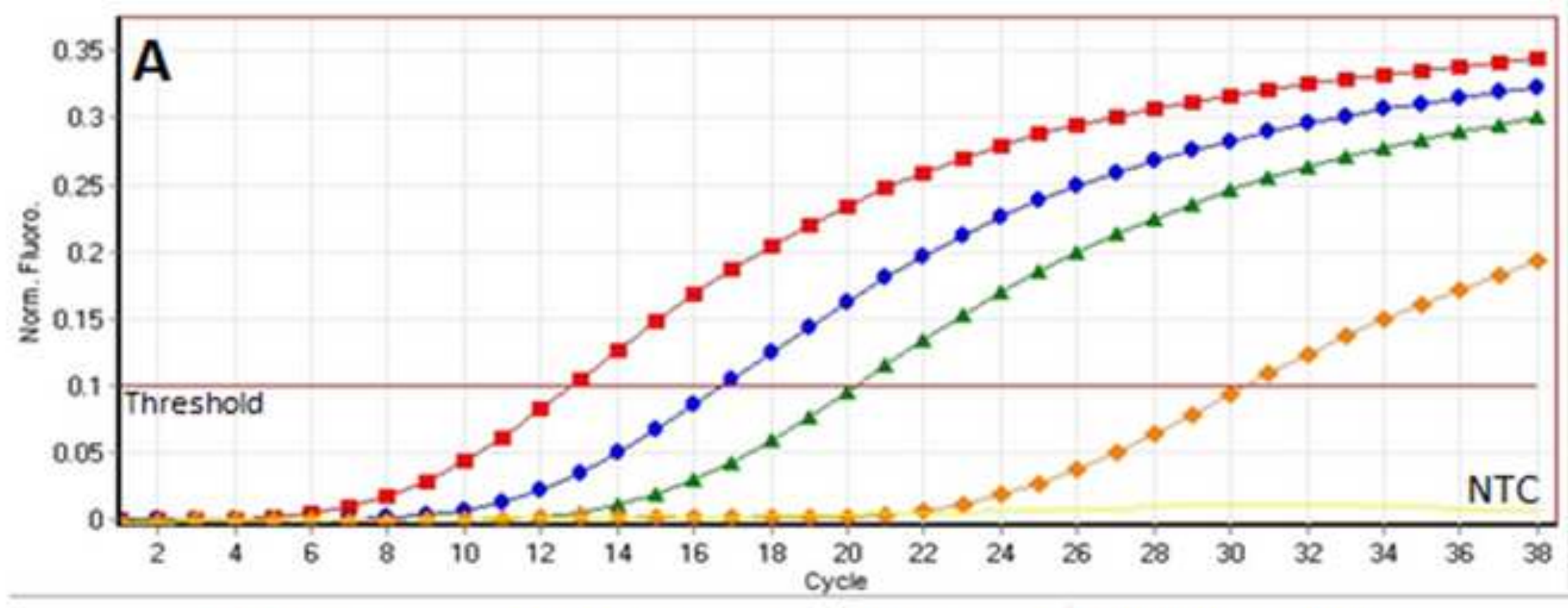

$=1 \mathrm{ng} \quad-100 \mathrm{pg} \quad \sim 10 \mathrm{pg} \quad$ Unknown cDNA

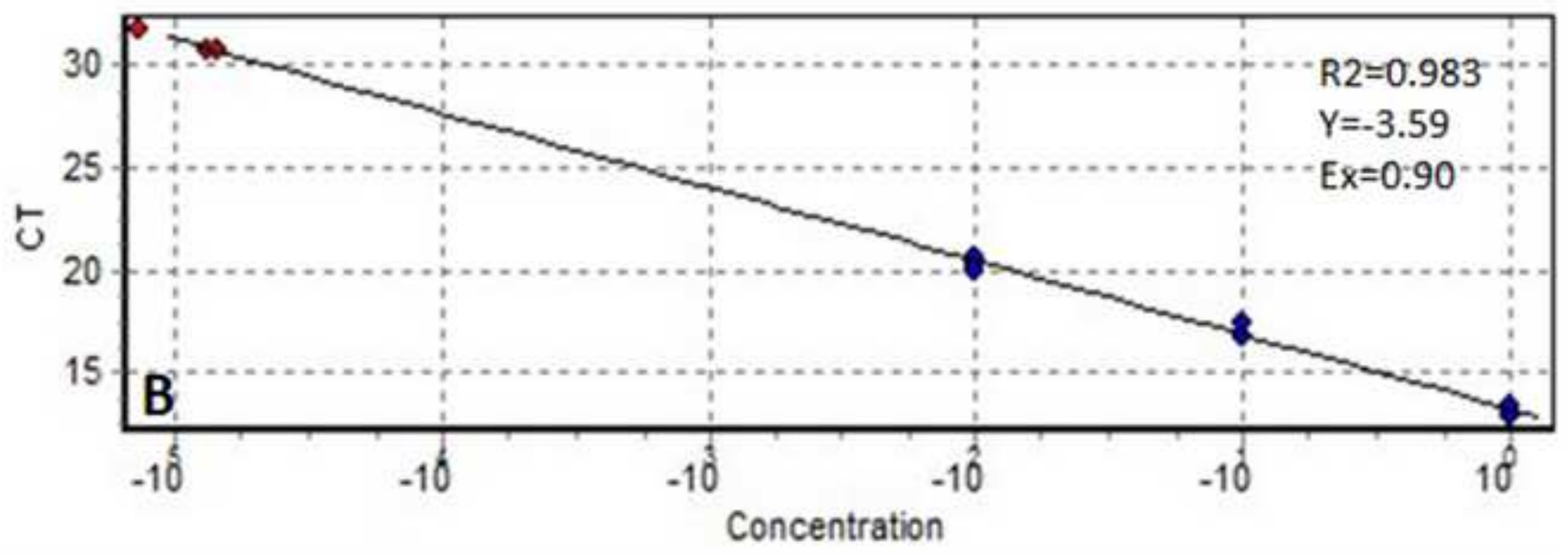




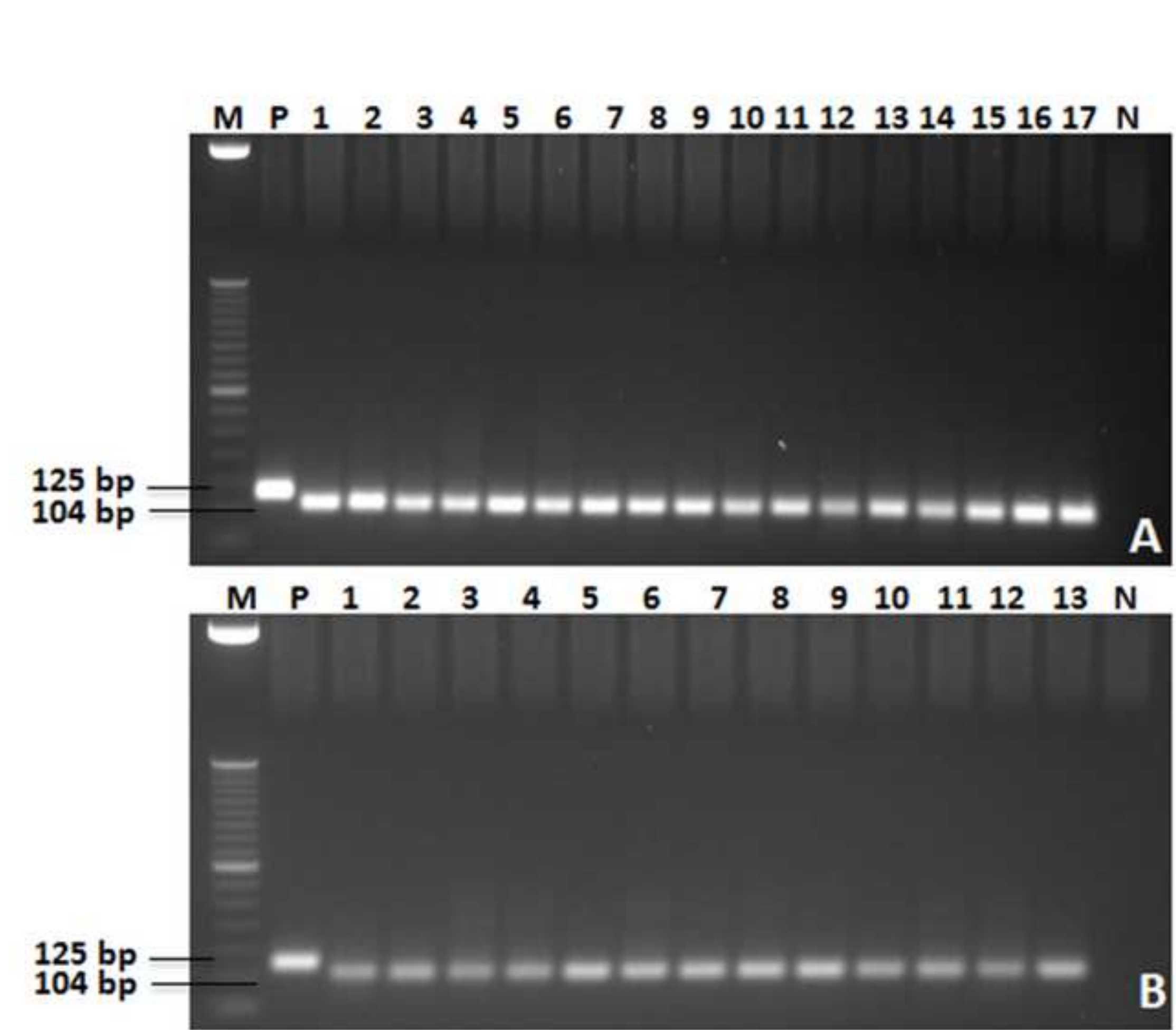

$\begin{array}{llllllllllllllll}M & P & 1 & 2 & 3 & 4 & 5 & 6 & 7 & 8 & 9 & 10 & 11 & 12 & 13 & \mathrm{~N}\end{array}$

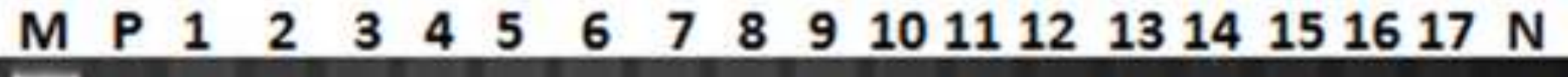

. .
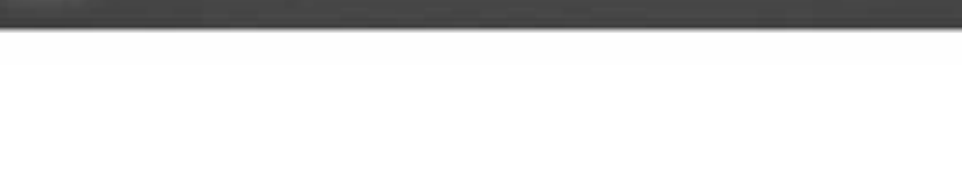
.

.




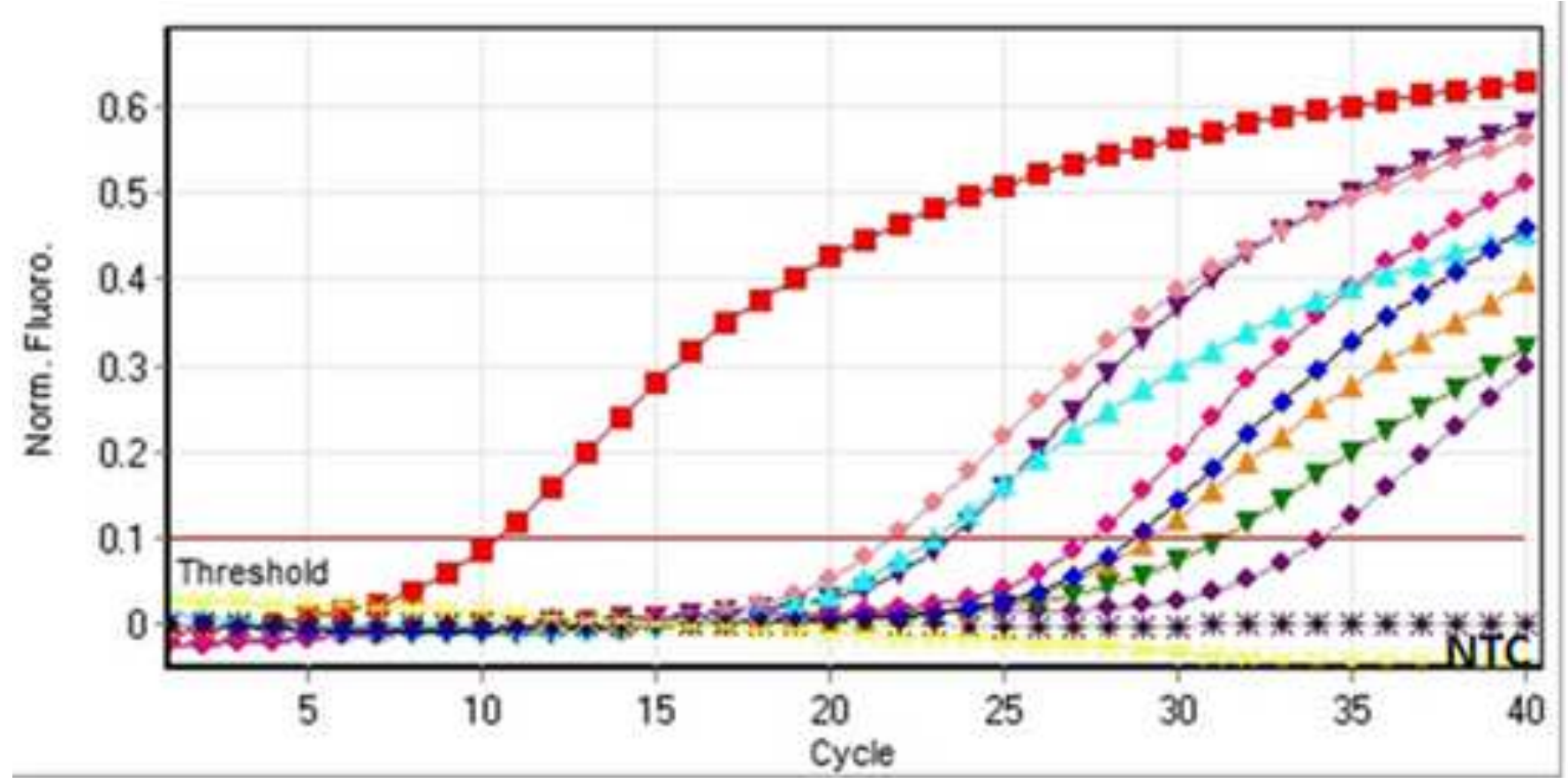

- APC (Artificial positive control)

y Positive control

\& R7

* R12

- R9

* R13

ar R3

T R6

- R5

* Negative control 

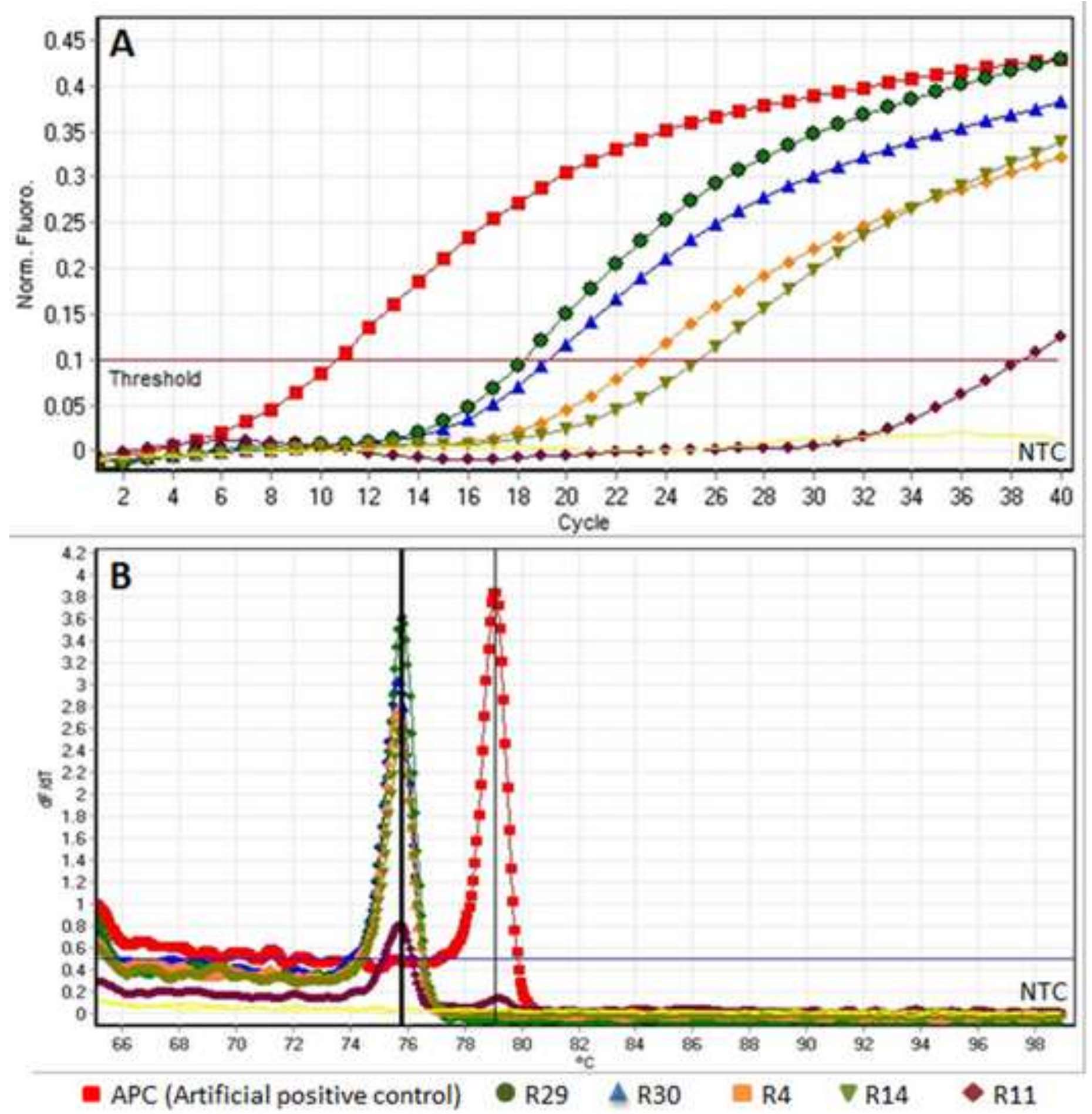

$\mathrm{APC}$ (Artificial positive control) - R29 $\Delta \mathrm{R} 30 \quad \mathrm{R} 4 \quad \nabla \mathrm{R} 14 \quad \bullet \mathrm{R} 11$

Figure 8

\section{8}

$$
0
$$

